\title{
Endpoint Reference
}

National Cancer Institute

\section{Source}

National Cancer Institute. Endpoint Reference. NCI Thesaurus. Code C80358.

A combination of Web service elements that define the address for a resource in a

Simple Object Access Protocol (SOAP) header. It consists of a Uniform Resource

Identifier (URI), message reference parameters, and data concerning the interface to be used. 